\title{
Modified Farmland Fertility Optimization Algorithm for Optimal Design of a Grid-connected Hybrid Renewable Energy System with Fuel Cell Storage: Case Study of Ataka, Egypt
}

\author{
Ahmed A. Zaki Diab ${ }^{1, *}$, Sultan I. EL-Ajmi ${ }^{2}$, Hamdy M. Sultan ${ }^{3}$, Yahia B. Hassan ${ }^{4}$ \\ Electrical Engineering Department, Faculty of Engineering, Minia University, 61111 Minia, Egypt ${ }^{1,2,3}$ \\ Department of Electrical and Electronic Engineering, Kyushu University, Fukuoka 819-0395, Japan ${ }^{1}$ \\ Electric Engineering Department, Higher Institute of Engineering, 61111 Minia, Egypt ${ }^{4}$
}

\begin{abstract}
In this paper, a Modified Farmland Fertility Optimization algorithm (MFFA) has been presented for optimal sizing of a grid connected hybrid system including photovoltaic (PV), wind turbines and fuel cell (FC). The system is optimal designed for providing a clean, reliable and affordable energy by adopting hybrid power systems. This system is very important for countries looking to achieve their sustainable development goals. MFFA is proposed in order to reduce the processing implementation time. The optimization method depends on the high reliability of the hybrid power supply, small fluctuation in the injected energy to the grid and high utilization of the wind and solar complementary characteristics. Moreover, MFFA is applied to minimize the cost of energy while satisfying the operational constraints. A real case study of a hybrid power system for Ataka region in Egypt is introduced to evaluate the performance of the proposed optimization method. Moreover, a comprehensive comparison between the proposed MFFA optimization technique and the conventional Farmland Fertility Algorithm (FFA) has been presented to validate the proposed MFFA.
\end{abstract}

Keywords-Photovoltaic; wind; fuel cell; renewable energy; hybrid energy system; modified farmland fertility optimization

\section{INTRODUCTION}

Recently, fossil fuels comprise the major energy sources in many parts all over the world. In fact, these fossil fuels can be exhausted and usually negatively affect the environment while they are being utilized into useful forms of energy [1]. Taking into account the drawbacks besides using fossil fuels in energy application, there is an urgent need to find cost-effective, reliable and clean alternative sources of energy. Renewable sources of energy such as PV, wind turbine and hydropower are the most attractive candidates for clean energy generation especially in low scale and isolated areas [2]. Each of these renewable energy sources has its unique character and principle of operation, which make it suitable for a certain site and application.

Because of the inherent fluctuations in solar and wind energy resources, the independent use of an individual power source usually results in a very large generation and storage system, which in turn requires a higher operating and life cycle cost $[5,6]$. Therefore, the hybrid solar-wind system is usually adopted, which can leverage the strengths of each technology to provide a more reliable and less costly power supply in remote areas [3, 4]. Energy storage systems such as batteries, fuel cells, flywheels, supercapacitors, molten salt, compressed air and hydroelectric pumped storage (HPS) can be a suitable solution to overcome the problems associated with the irregular nature of renewable sources.

Hydrogen tanks as a mean of energy storage in renewable energy systems has been proposed in many research studies [79]. Hydrogen storage performs well in both long and shortterm purposes and in some cases for enhancement of the dynamic performance of the system, super capacitors are advisable to be integrated [10]. In comparison with diesel generator as a method of energy storage, hydrogen-based energy storage systems do not need any external supply of fuel and no greenhouse emissions are exhausted into the atmosphere. In addition, due to the continuous increase in the fuel cost and the observable reduction in the cost of FC, it is expected that the hydrogen storage systems will be economically feasible for application as a method of electric energy storage in the form of hydrogen gas [11].

In hybrid renewable energy systems based on hydrogen storage, during the hours of excess energy from the PV and wind systems, electrolyzer coverts the surplus electrical energy into hydrogen stored in the hydrogen tanks. When the peak demand for electricity occurs and the wind speed and solar radiation are not sufficient to satisfy the load demand by converting the stored hydrogen into electricity through the FC [12].

Due to the fact that hybrid PV/wind power systems depend mainly on sources having intermittent characteristic (solar radiation and wind speed), it is a great challenge to design such a system with an acceptable reliability when considering the investment and operating costs of each component in the system. Therefore, the main goal is the optimal configuration of an economic and reliable power supply. In the literature, there are many research papers, which offer different methods and algorithms for optimal design of hybrid PV/wind power systems [13-28]. 
In $[13,14]$ the optimal sizing of a PV/wind/diesel hybrid system was presented using Strength Pareto evolutionary algorithm by formulating two objective functions, minimization of system cost and greenhouse gases emissions. In [15-17], Genetic algorithm (GA) was used for optimal sizing and configuration of a hybrid $\mathrm{PV} /$ wind power system with battery storage under different objective functions; the reliability of the system under weather conditions variations, minimizing the annual cost of the system and to minimize the loss of power supply probability (LPSP). Particle Swarm Optimization (PSO) has been used in many research studies for optimal sizing of hybrid renewable energy systems [18-20]. Simulated Annealing (SA) optimization strategy was used for optimal sizing of hybrid PV/wind energy conversion system, while the objective function was to minimize the total energy cost of the hybrid system [21]. The response surface methodology (RSM) was used for optimizing the size of an autonomous $\mathrm{PV} /$ wind system with energy storage in some studies [22]. The results obtained from RSM optimization were confirmed using autonomy analysis and loss of load probability, then the results of this work were used in [21] to be compared with the results obtained from simulated annealing optimization. In [23] Pattern Search (PS) optimizer and

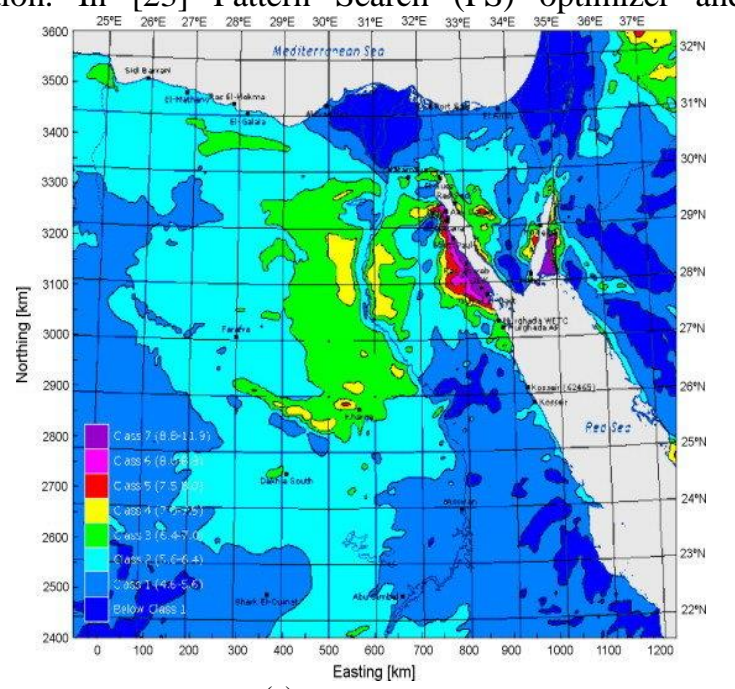

(a) sequential Monte Carlo Simulation (SMCS) are combined to obtain the minimum total cost of the system and satisfy the reliability requirements from the consumer side. A comparison with a hybrid GA-SMCS was also performed, from which the PS-SMCS gave a better performance. In [24] cuckoo search optimization algorithm has been used for optimal sizing of an isolated $\mathrm{PV} / \mathrm{wind} / \mathrm{diesel} /$ battery energy system, while the proposed technique provided high accuracy when compared with GA and PSO. Multi-Objective Self-Adaptive Differential Evolution (MOSaDE) algorithm has been used for optimal sizing and operation of a hybrid PV/wind/diesel microgrid system with battery storage for the city of Yanbu, Saudi Arabia, while, the multi-objective optimization approach is used to reduce the computational time [25]. Optimal sizing and placement of a grid-connected PV-wind-battery storage microgrid using Artificial Bee Colony optimization technique, while the IEEE 30-bus system was used for the application of the optimal operation [26]. In [27, 28] the Hybrid Optimization of Multiple Energy Resources (HOMER) software has been used for optimum sizing of hybrid wind/PV/diesel system in Malaysia in which the weather conditions, maximum availability and minimum cost were considered respectively.

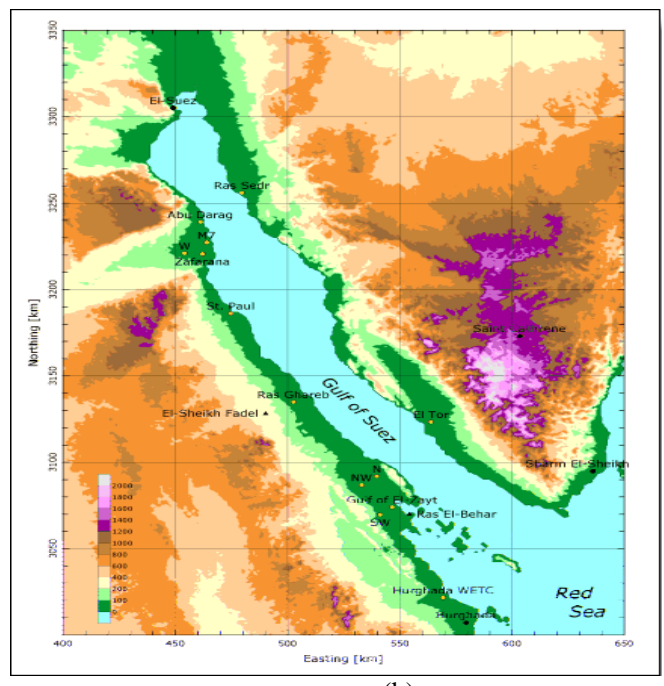

(b)
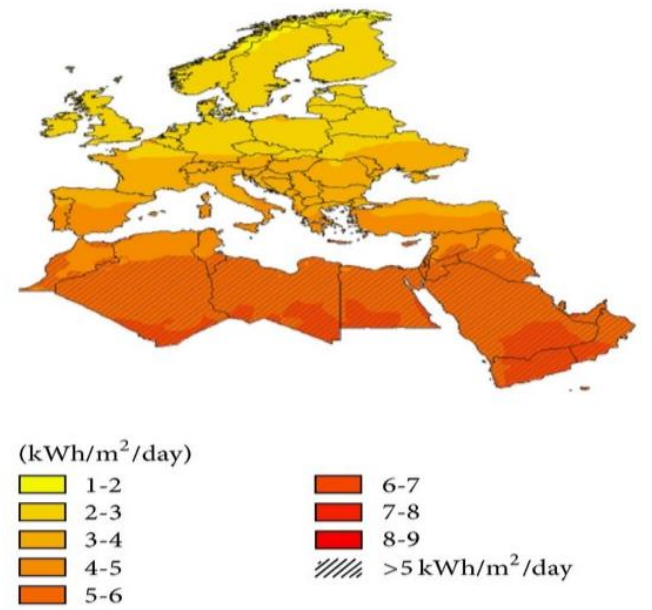

(c)

Fig. 1. (a) Wind Resource Map of Egypt: mean Wind Speed at $50 \mathrm{~m}$ a.g.1. Determined by Mesoscale Modelling (Wind Atlas for Egypt, 2006), (b) Wind Atlas of Gulf of Suez, Egypt. (c) Egypt's Solar Potential. 
This paper investigates on the economical design of a griddependent hybrid PV/wind power system with electrolyzer, hydrogen tank and fuel cell. In this way, a MFFA has been exploited for minimizing the cost of energy (COE) generated from this system over its 25 years lifetime and subjected to reliability constraints in the form of LPSP. This study is in line with the plans of the Egyptian government to encourage Egyptian and foreign companies to expand for establish renewable energy projects where it has developed catalyst laws and legislations in this field [37]. The current sites of renewable energy projects in Egypt, mostly concentrated in the Gulf of Suez and south Egypt because of its high wind speed and high solar radiation [37]. Moreover, the Solar and wind speed spectrum have been shown in Fig. 1. The figure shows that the Gulf of Suez area is very large and promised to implement wind energy power plant. Also, the figure shows this region is suitable for implementation of the PV power plant. Moreover, this region has three wind power plant in Gabal Elzeit with $380 \mathrm{MW}$ total power and a grid connected PV project around $20 \mathrm{MW}$, in Hurghada [37]. Therefore, the area of Ataka at the Gulf of Suez has been chosen to be the place of study where it lies on the shore of the Red sea (latitude 30.0, longitude 32.5) [29]. The system cost includes the annual interest of capital investment cost, operation and maintenance, replacement cost, cost of energy sold and purchased from the external grid as well as the penalty cost due to unacceptable reliability and fluctuation rate in the energy exchange with the utility grid.

The main contribution of this paper can be written as follows:

- A MFFA has been presented; this modification is proposed to reduce the processing time of the recent FFA.

- The MFFA algorithm has been applied for design the Hybrid energy system. Moreover, the results have been analyzed and compered with these of the conventional one.

- The objective function consists of two terms; the cost of energy and LPSP.

- A real case of study has been selected in Egypt to validate the presented optimization technique.

The paper is organized as follows: Section 2 briefly describes the subsystems of the hybrid system and their corresponding models. The operation strategy is demonstrated in Section 3. Optimization problem statement, FFA and MFFA are discussed in Section 4. Simulation results and discussions are summarized in Section 5. Finally, Section 6 is devoted to conclusion.

\section{CONSTRUCTION DESCRIPTION OF THE PROPOSED SYSTEM}

A simplified single line diagram of the proposed gridconnected hybrid system is shown in Fig. 2. The proposed system includes seven main components in addition to the $\mathrm{AC}$ and DC buses. The system includes wind turbine generators, photovoltaic arrays, electrolyzer, hydrogen tanks, fuel cells, converter and the electric utility grid. During the hours of low demand of electric energy and when the generated power from the renewable sources exceeds the load demand the excess energy is supplied to the electrolyzer to store the energy in the form of chemical energy (hydrogen) in hydrogen tanks. If the redundant energy is higher than that required to fully charge the hydrogen tanks, then the surplus power is supplied to the grid. On the other hand, during the nighttime, in the time of maximum load, when the generation is less than the load demand, the energy stored in the hydrogen tanks is applied to the fuel cell to convert it again to electric energy serving the load. In the case of insufficient supply from the renewable sources, the energy deficit is covered by the electric grid. The models of the previously mentioned components are described in the following sections.

\section{A. PV System}

The output power generated from a PV module in terms of the solar radiation and the ambient temperature can be expressed as [29]:

$$
P_{P V}(\mathrm{t})=n_{P V} P_{P V_{-} \text {rated }} \eta_{P V} \eta_{\text {Wire }} \frac{G(t)}{G_{\text {nom }}}\left(1-\beta_{T}\left(\mathrm{~T}_{C}(t)-\mathrm{T}_{\text {nom }}\right)\right)
$$

where, $n_{P V}$ is the number PV modules, $P_{P V_{-} \text {rated }}$ is the rated power of the PV module at standard operating conditions $\left(G_{\text {nom }}\right.$ $=1000 \mathrm{~W} / \mathrm{m}^{2}$ and $\left.T_{\text {nom }}=25^{\circ} \mathrm{C}\right), \eta_{P V}$ is conversion efficiency of the PV module, and $\eta_{\text {wire }}$ is the wire efficiency. $G(t)$ is the ambient solar radiation intensity, $G_{\text {nom }}$ is the intensity of solar radiation under standard conditions, $\beta_{\mathrm{T}}$ is the temperature coefficient of power of the selected PV module, $T_{c}(t)$ is the cell temperature, and $T_{\text {nom }}$ is the cell temperature under standard conditions of operation, respectively.

The efficiency of the PV modules inherent includes the efficiency of the maximum power point tracking (MPPT) system. As stated in [30], using the MPPT system will increase the energy generated from the photovoltaic modules by about $30 \%$, it is economically feasible to incorporate them in such hybrid systems. As a result, in the system under study, it is supposed that the PV modules are fixed on tracking system having an efficiency of $95 \%$.

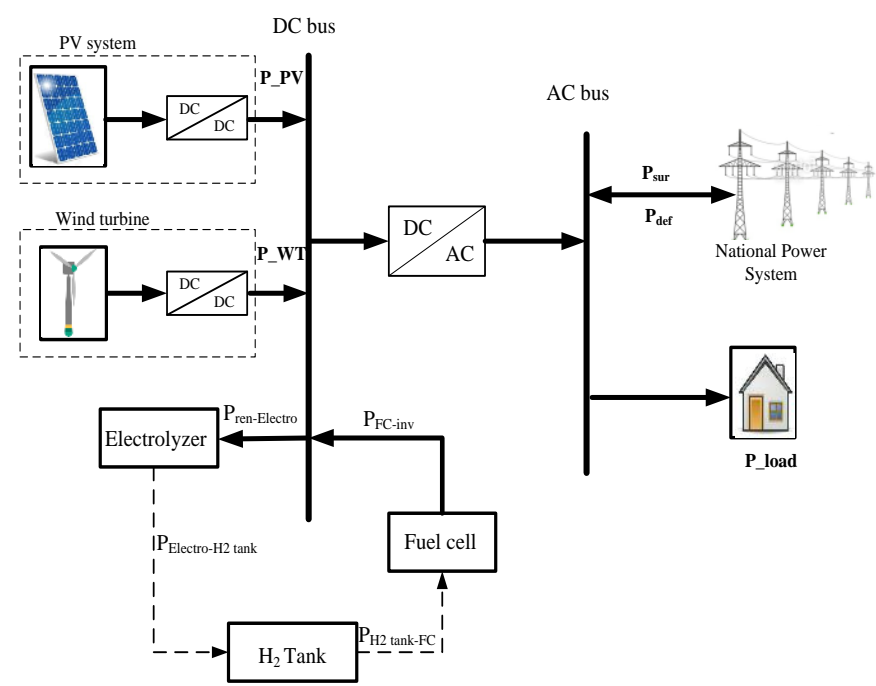

Fig. 2. Single Line Diagram of the Grid-Dependent Proposed Hybrid System. 


\section{B. Wind Turbine}

Depending on the fundamentals of wind energy, the expected energy supplied by a wind turbine can be described as follow [29]:

$$
P_{W T}= \begin{cases}0 & u(t)<u_{\text {cut-in }} \\ \frac{n_{\text {wind }} \eta_{\text {wind }} P_{R_{-} W T}\left(u^{2}(t)-u_{\text {cut }- \text { in }}^{2}\right)}{\left(\mathrm{u}_{\text {rated }}^{2}-u_{\text {cut }- \text { in }}^{2}\right)} & u_{\text {cut-in }}<u(t)<u_{\text {rated }} \\ n_{\text {wind }} \eta_{\text {wind }} P_{R_{-} W T} & u_{\text {rated }}<u(t)<u_{\text {cut }- \text { off }} \\ 0 & u(t)>u_{\text {cut }- \text { off }}\end{cases}
$$

where, $P_{W T}$ is the actual power generated from wind turbine, $P_{R_{-} W T}$ is the wind turbine rated power, $n_{\text {wind }}$ is the number of wind turbine, $\eta_{\text {wind }}$ is the efficiency of the wind system. $u(t)$ is the wind speed at time $\mathrm{t}, u_{c u t-i n}$ is the cut-in wind speed, at which the turbine start operation, $u_{\text {rated }}$ is the wind speed at rated power, and $u_{\text {cut-off }}$ is the cut-off wind speed, after which the wind turbine must be shut down for safety reasons. In this study, Bergey Wind Power's BWC Excel-R/48 wind turbine, which has a rated power of $7.5 \mathrm{~kW}$, which provides $48 \mathrm{~V}$ DC is proposed. The detailed model of the wind turbine suggested in this study is described in [11]. Considering the fact that the wind speed changes with height, the wind speed at a desired hub height as a function of the wind speed measured at the anemometer height is given as follow [30]:

$$
\frac{u_{2}}{u_{1}}=\left(\frac{h_{2}}{h_{1}}\right)^{\alpha_{W T}}
$$

where, $u_{2}$ is the wind speed at the wind turbine hub with height $h_{2}, u_{l}$ is the wind speed at the reference point $h_{l}$, and $\alpha_{W T}$ is the friction coefficient. According to the recommendations of IEC standards, the value of coefficient of friction is taken as 0.11 for extreme wind conditions, and 0.20 for normal wind conditions. The renewable power injected to the DC busbar is the sum of the power generated from the PV panels and the wind turbine generators. The renewable power takes two different streams. The first part $\left(P_{\text {ren-inv }}\right)$ flows through the DC/AC inverter to supply the load connected at the AC bus and the surplus power fed into the grid. The second stream $\left(P_{\text {ren-Electro }}\right)$ is used by the electrolyzer for producing hydrogen.

\section{Electrolyzer}

The electrolyzer uses the process of water electrolysis to decompose the water to its original molecules, hydrogen and oxygen, using a DC current flows between two electrodes. Then the hydrogen is collected around the surface of the anode. As stated in [31] in most water electrolyzer, the produced hydrogen is collected at a pressure of 30 bar, which is higher than the reactant pressure of the hydrogen supplied to the Proton Exchange Membrane Fuel Cell (PEMFC), which is around 1.2 bar. The hydrogen produced from the electrolyzer might be directly applied to the hydrogen tank as in most studies, or the pressure of the produced hydrogen is raised to about 200 bar using a compressor in order to raise the energy stored density [31]. In other studies, the hydrogen obtained from the electrolyzer is supplied to a low pressure tank, then when the tank is fully charged, a compressor is used to pump the stored hydrogen to a high pressure tank. Thus, the energy consumed by the compressor is reduced as it is not in operation all time [12]. In this study, the hydrogen produced is directly injected to the hydrogen tank. The electrolyzer is modelled by means of the power transferred from the dc bus-bar to the hydrogen tank and is described as follows $[11,33]$ :

$$
P_{\text {Electro-tan } k}=P_{\text {ren-Electro }} \times \eta_{\text {Electro }}
$$

where, $P_{\text {Electro-tank }}$ is the output power of the electrolyzer, which is supplied into the hydrogen tank, $P_{\text {ren-Electro }}$ is the input power to the electrolyzer, and $\eta_{\text {Electro }}$ is the efficiency of the electrolyzer, which is supposed to have a constant value for the whole simulation time.

\section{Hydrogen Tank}

In this paper, the hydrogen tank is modelled by means of the amount of energy stored in the hydrogen tank and at any time of simulation $t$ is mathematically calculated from the following equation [33]:

$$
E_{\tan k}(t)=E_{\tan k}(t-1)+\left(P_{\text {Electro- } \tan k}(t)-\frac{P_{\tan k-F C}(t)}{\eta_{\text {storage }}}\right) \times \Delta t
$$

where, $E_{\text {tank }}(t)$ is the energy stored in the hydrogen tank at any time t, $E_{\text {tank }}(t-1)$ is the energy stored in the tank at time (t$1), P_{\text {tank-FC}}(t)$ is the equivalent power drawn from the hydrogen tank and injected into the fuel cell, and $\eta_{\text {storage }}$ is the efficiency of the storage tank and it represents the losses due to selfdischarge of the tank itself and it is taken as $95 \%$ for all operating scenarios [32]. $\Delta t$ is the time interval in the simulation process, which is considered equal to an hour in this paper. At any simulation time $t$ the mass of the hydrogen stored in the tank is calculated as follow [33]:

$$
M_{\tan k}(t)=\frac{E_{\tan k}(t)}{H H V_{H_{2}}}
$$

where, $H H V_{H 2}$ is the higher heating value (HHV) of the hydrogen. HHV of a certain fuel is defined as the amount of heat produced by a specific amount at standard temperature $\left(25^{\circ} \mathrm{C}\right)$, when it is combusted and the products of the combustion process are returned again to $25^{\circ} \mathrm{C}$. According to [34], the value of HHV for hydrogen is taken as $39.7 \mathrm{kWh} / \mathrm{m}^{2}$. The stored energy in the tank at any time t occurs between a predefined upper and lower limits. The upper limits are described by the maximum capacity of the tank. For some problems associated with the nature of the hydrogen itself, it is recommended that a small amount of the hydrogen stored is not discharged, which forms the lower limit of the hydrogen tank (here 5\%). Therefore,

$$
M_{\tan k, \min } \leq M_{\tan k}(t) \leq M_{\tan k, \max }
$$

where, $M_{\text {tank,min }}$ is the lower limit of the hydrogen tank, $M_{\text {tank }}(t)$ is the mass of hydrogen stored in the tank at any time t, and $M_{\text {tank,max }}$ is the upper limit of the hydrogen tank. 


\section{E. Fuel Cell}

The basic operation of the hydrogen fuel cell is extremely simple. In the hydrogen FC the electrolysis is being reversed the hydrogen and oxygen are recombining, and an electric current is being produced. During this chemical reaction, electric energy is produced in the form of electrons, which are released in the process of ionization of the hydrogen. PEMFC is commercially produced in high generating capacities and reliable and good dynamic response thanks to its short power release time of about 1-3 s [31]. In this study the efficiency of the fuel cell is assumed to be constant and taken as $50 \%$, then its output can be simply calculated as a function of the input power and efficiency. Therefore,

$P_{F C-i n v}=P_{\tan k-F C} \times \eta_{F C}$

where, $P_{\text {tank-FC }}$ is the input power to the fuel cell, which describes the mass of hydrogen consumed in the chemical reaction, and $\eta_{F C}$ is the efficiency of the fuel cell.

\section{F. DC/AC Converter}

The inverter is used to convert the DC power from the renewable sources and the fuel cell into the form of AC power to cover the load demand and the excess power is supplied to grid. According to [11], the efficiency of the inverter $\left(\eta_{i n v}\right)$ is assumed to be constant at $90 \%$ for the whole simulation time. Therefore, the power output from the inverter is described as follows:

$$
P_{i n v-A C}=\left(P_{F C-i n v}+P_{r e n-i n v}\right) \times \eta_{i n v}
$$

where, $P_{F C \text {-inv }}$ is the output power from the fuel cell, and $P_{\text {ren-inv }}$ is the power generated from the renewable sources and directly supplied to the load.

\section{OPERATION STRATEGY}

The operation of the proposed hybrid renewable system is summarized in the following operation scenarios.

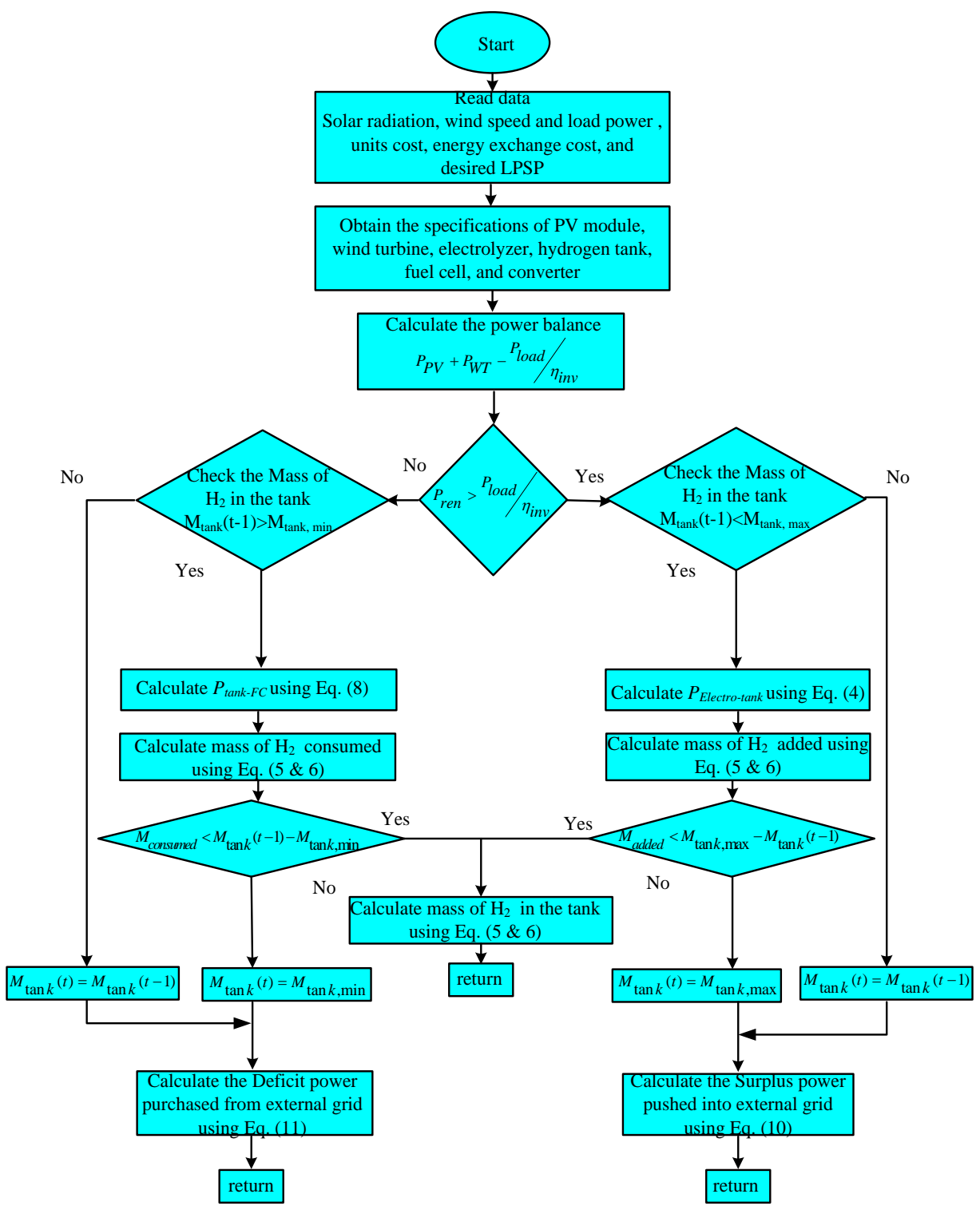

Fig. 3. Flowchart Describing the Operation of the Hybrid System. 
If the generated power from the renewable sources $\left(P_{\text {ren }}(t)\right.$ $\left.=P_{P V}(t)+P_{W T}(t)\right)$ equal to the load power $\left(P_{\text {load }}(t)\right), P_{\text {ren }}(t)=$ $P_{\text {load }}(t) / \eta_{\text {inv }}$, then the whole renewable power is supplied to the load.

If $P_{\text {ren }}(t)>P_{\text {load }}(t) / \eta_{\text {inv, }}$, the excess power is applied to the electrolyzer. If the difference exceeds the rated power of the electrolyzer, then the surplus power $\left(P_{\text {sur }}(t)\right)$ is injected into the electric grid. Therefore,

$$
P_{\text {sur }}(t)=P_{\text {ren-inv }}(t) \times \eta_{\text {inv }}-P_{\text {load }}(t)
$$

If $P_{\text {ren }}(t)<P_{\text {load }}(t) / \eta_{\text {inv }}$, then the shortage in load demand is covered by the fuel cell. If the power needed to cover the load exceeds the rated of the fuel cell, then the electric grid supplies the power deficit $\left(P_{\text {def }(t)}\right)$. Therefore,

$$
P_{\text {def }}(t)=P_{\text {load }}(t)-\left(P_{\text {ren-inv }}(t)+P_{F C-i n v}(t)\right) \times \eta_{i n v}
$$

A flowchart describing the operation of the proposed hybrid system is shown in Fig. 3.

\section{Optimization PRoblem}

\section{A. Cost of Energy Generated from the Proposed Hybrid System}

The annual interest of capital cost for each component in the system as apart from the initial investment cost $\left(\mathrm{C}_{\text {cap__ }}\right)$ for each component $i$ is calculated as follows [24]:

$$
C_{\text {ann_cap_i } i}=C_{c a p_{-} i} * \operatorname{CRF}\left(r, M_{i}\right)
$$

where, $i$ refers to each component in the system including; wind turbine, photovoltaic system, electrolyzer, hydrogen tank, fuel cell, and DC/AC converter. $C R F$ is the capital recovery factor, $r$ is the rate of interest (here $=0.06$ ), and $M_{i}$ is the lifetime of each sub-system [24]. CRF is calculated from the following formula [24]:

$$
\operatorname{CRF}\left(r, M_{i}\right)=\frac{r(1+r)^{M_{i}}}{(1+r)^{M_{i}}-1}
$$

The operating and maintenance cost $\left(C_{o \& m}\right)$ of the hybrid renewable energy system is the major running cost of the system as there is no fuel cost. Starting from the fact that each component in the power system has its own lifetime, which is different from the lifetime of the whole system as an economic project $\left(M_{s y s}=25\right.$ years), so that there is a need for replacement for the individual subsystems. The annual cost for replacement $\left(C_{\text {rep_ann }}\right)$ for each subsystem i is calculated as follows [35]:

$C_{\text {ann_rep }}=C_{\text {rep } \_i} \frac{\left(M_{\text {sys }}-M_{i}\right)}{M_{i}}$

In the case of a grid connected power system, the fluctuation of the injected energy into the grid and LPSP causes a penalty cost if they exceed the predefined values. In this paper, LPSP is limited to not exceed the predefined value $(\beta \mathrm{L}=0.05)[35]$ and it is calculated according to the following formula [35]:

$$
L P S P=\frac{\sum_{i=1}^{8760}\left[\mathrm{P}_{\text {load }}\left(\mathrm{t}_{i}\right)-\left(\mathrm{P}_{P V}\left(\mathrm{t}_{i}\right)+\mathrm{P}_{W T}\left(\mathrm{t}_{i}\right)+\mathrm{P}_{F C-i n v}\left(\mathrm{t}_{i}\right)\right)\right]}{\sum_{i=1}^{8760} \mathrm{P}_{\text {load }}\left(\mathrm{t}_{i}\right)}
$$

According to [35] the maximum power fluctuation rate should not exceed $33 \%$ of the installed power of the system for an interval of 10 minutes. The power fluctuation rate $\left(D_{g s}\right)$ is calculated as follows [35]:

$D_{g s}=\frac{P_{\text {sur_max }}-P_{\text {sur_min }}}{\Delta t}$

where, $P_{\text {sur } \max }$ is the maximum value of the power supplied to grid and $P_{\text {sur } r_{-} \text {in }}$ is the minimum value of the surplus power. During operation the fluctuation rate is limited to the predefined value $\beta_{g}$. If the value of $L P S P$ and $D_{g s}$ exceed their suggested values, then the penalty cost $\left(C_{p c}\right)$ of the system is calculated according to the following formula [35]:

$$
\begin{aligned}
C_{p c}= & C_{p c_{-} 1} \times\left(\mathrm{LPSP}-\beta_{L}\right) \times \sum_{i=1}^{N} P_{\text {load }}\left(\mathrm{t}_{i}\right) \\
& +C_{p c_{-} 2} \times \frac{D_{g s}-\beta_{g}}{\beta_{g}} * 100
\end{aligned}
$$

Where, $C_{p c_{-}-1}$ is the penalty cost for the shortage of supply and $C_{p c_{-} 2}$ are the penalty cost for fluctuation in the supply. During simulation and the operation of the optimal sizing model the penalty costs are considered as $C_{p c_{-} l}=100 \$ / \mathrm{kWh}$ and $C_{p c_{2} 2}=50000 \$ 1 \%$.

To make a full use of the PV and wind complementary characteristics, the relative fluctuation rate is adopted for the renewable generation with respect to the load power [35]:

$D_{\text {load }}=\frac{\sqrt{\frac{1}{N} \sum_{i=1}^{N}\left(P_{P V}\left(\mathrm{t}_{i}\right)+P_{W T}\left(\mathrm{t}_{i}\right)-P_{\text {load }}\left(\mathrm{t}_{i}\right)\right)^{2}}}{\bar{P}_{\text {lood }}}$

where, $\bar{P}_{\text {load }}$ is the average load power. Smaller value of $D_{\text {load }}$ means that the power generation is closer to the load demand and ensures better utilization of the sources. The hybrid system will ensure a full utilization of renewable sources characteristics, if the relative fluctuation is smaller than the allowable reference $\left(\varepsilon_{L}=2\right)$ [35].

When the power generated from the renewable sources is greater that the load demand and the power consumed by the electrolyzer, the surplus is sold to the grid $\left(C_{g s}\right)$. In opposite when the renewable generation and the power supplied by the fuel cell do not cover the load demand, the deficit is purchased from the grid $\left(C_{g p}\right)$. The cost of energy sold and purchased is calculated as follows:

$$
\begin{aligned}
& C_{g p}=N_{g p} \times C_{p} \\
& C_{g s}=N_{g s} \times C_{s}
\end{aligned}
$$

where, $C_{p}$ (here $0.08 \$ / \mathrm{kWh}$ ) the cost of $\mathrm{kWh}$ purchased from the external grid, $C_{s}$ (here $0.2 \$ / \mathrm{kWh}$ ) is the cost of $\mathrm{kWh}$ 
supplied to the grid and $N_{g p}$ is the total units purchased from the grid, and $N_{g s}$ is total energy units supplied to the grid. The specific characteristics of components applied in system simulation are depicted in Table I [11]. The annual cost of the hybrid renewable system $\left(C_{\text {ann_tot }}\right)$ is calculated as the sum of the individual costs for the whole system [35]:

$$
\begin{aligned}
C_{a n n \_t o t}= & C_{a n n \_c a p}+C_{a n n_{-} r e p} \\
& +C_{\mathrm{O} \& \mathrm{M}}+C_{p c}+C_{g p}-C_{g s}
\end{aligned}
$$

The net present cost (NPC) of the system is calculated as follow [24]:

$$
N P C=\frac{C_{\text {ann_tot }}}{C R F}
$$

The cost of energy (COE) from the hybrid system in $(\$ / \mathrm{kWh})$ and formulated in the following equation $[24,35]$ :

$$
C O E=\frac{C_{\text {ann_tot }}}{\sum_{h=1}^{h=8760} P_{\text {load }}}=\frac{N P C}{\sum_{h=1}^{h=8760} P_{\text {load }}} \times C R F
$$

\section{B. Objective Function and Constraints}

In this paper, as introduced a Minimizing the objective function of COE, LPSP for the optimization algorithm as a function in Wind turbine, PV array, Electrolyzer, hydrogen tank, FC and DC/AC converter can be expressed as:

$\min f=\min \left(o b j_{-} f u n c\right)$

where;

$o b j_{-}$func $=\lambda_{1} * C O E+\lambda_{2} *$ LPSP

$\lambda_{1}, \lambda_{2}$ are chosen as trial and error to reach the best results. In this work, the values of $\lambda_{1}$, and $\lambda_{2}$ are 0.5 , and 0.5 respectively.

MFFA optimization algorithm has been used for optimal sizing of the proposed hybrid system under the following constraints:

$$
\begin{gathered}
L P S P \leq \beta_{L} \\
M_{\tan k, \min } \leq M_{\tan k}(t) \leq M_{\tan k, \max } \\
D_{g s} \leq \beta_{g} \\
D_{\text {load }} \leq \varepsilon_{L}
\end{gathered}
$$

\section{Farmland Fertility Algorithm}

In this paper, the recent optimization algorithm of farmland fertility, which is presented for the first time in [36], is applied for design the renewable energy resources system. The farmer in their land bases the idea of FFA optimization algorithm on the determination of the quality the soil of each region of farmland. The main reason of variations of Soil's quality is based on consisting and adding of special materials. Therefore, farmers use different materials to improve the quality of farmland. In other words, these materials when added to the soil in farmland, they may improve or reduce the quality of the soil. The determination of these materials to improve the soil quality is based on trying materials based on the farmers experience with each type of soil and the previous results of improving in the soil quality for each time. There are main steps for determine the best quality and best materials for improving the soil quality, which can be mathematically described as follows:

1) First stage initialization: At this stage, the generation of the initialized population is based on the following criteria:

- Taking the number of sections of farmland in to consideration (number of parts for optimization problem and is expressed by $\mathrm{k}$ ).

- Considering the number of available solutions in each section, (the number of existing solutions in each section of farmland and is expressed by $n$ ).

The following mathematical equation is to describe this first stage to generate the total number of population $\mathrm{N}$ :

$$
N=k * n
$$

where, $k$ is an integer number and greater than zero. The constant $\mathrm{k}$ is considered for partition of search space (As farmers divide their land into different parts). Its value is between 1 and $N$. In this paper, it is determined by trial and error to reach the best solution and its value equals to 2 . In [36], the authors refer to if the value is greater than 8, the FFA algorithm gives very poor performance. So, $\mathrm{k}$ may be considered as $2 \leq k \leq 8$. Moreover, $\mathrm{n}$ is an integer number. It is also determined by trial and error in this work. It describes the available solutions from each search space. The following equation generates the random solution in the first stage taking into consideration the upper and lower limits of the each variable $\mathrm{Uj}$ and $\mathrm{Lj}$, respectively.

$$
X_{i j}=L_{j}+\operatorname{rand}(0,1) \times\left(U_{j}-L_{j}\right)
$$

TABLE I. SPECIFICATIONS OF THE SYSTEM COMPONENTS [11]

\begin{tabular}{|l|l|l|l|l|l|l|}
\hline Component & $\begin{array}{l}\text { Capital cost } \\
\text { (US\$/unit) }\end{array}$ & $\begin{array}{l}\text { Replacment cost } \\
\text { (US\$/unit) }\end{array}$ & $\begin{array}{l}\text { O\&M (US\$/ } \\
\text { unit-yr) }\end{array}$ & Lifetime (yr) & Efficiency (\%) & Unit \\
\hline Wind turbine & 19400 & 15000 & 75 & 20 & - & $7.5 \mathrm{~kW}$ \\
\hline PV array & 7000 & 6000 & 20 & 20 & - & \\
\hline Electrolyzer & 2000 & 1500 & 25 & 20 & $1 \mathrm{~kW}$ & 75 \\
\hline Hydrogen tank & 1300 & 1200 & 15 & 20 & $1 \mathrm{~kW}$ & 95 \\
\hline Fuel cell & 3000 & 2500 & 175 & 5 & $1 \mathrm{~kg}$ & 50 \\
\hline DC/AC converter & 800 & 750 & 8 & 15 & 90 & $1 \mathrm{~kW}$ \\
\hline
\end{tabular}


where, $j=[1 \ldots . . . D]$ represents dimension of the variables $x$ in the optimization problem and is based on the total number of population and is equal to [1...N].

In this paper, for the presented problem the $\mathrm{x}$ represents the size of RES plants which are (number of PV units, number of wind turbines, rated power of the electrolyzer, maximum capacity of the hydrogen tank, rated power of the fuel cell, and rated power of the $\mathrm{DC} / \mathrm{AC}$ converter) which is required to determine the best optimal size RES plants.

Fig. 4 shows that the farmland is allocated into 3 sections, each section has its own local memory and a global memory and part A has soil with lowest quality. In the following part, the mathematical expression of each stage will be expressed.

2) Second stage: determination of the quality of soil in each section of farmland: In this stage, the fitness of all the existing solutions in the search area have been evaluated. Moreover, the soil quality of each of the parts of the farmland (sections of the search space) can be determined as following:

Section $_{s}=X(a j), a=n^{*}(s-1): n * s s=\{1,2, \ldots \ldots k\}$,

$j=\{1,2, \ldots \ldots . .4\}$

The average value of the existing solutions in each part of the farmland is used to determine the quality of each section.

Section $_{s}=X(a j), a=n^{*}(s-1): n * s s=\{1,2, \ldots \ldots k\}$,

$j=\{1,2, \ldots \ldots . .4\}$

At this stage of the farmland fertility the individual sections of the farmland have been determined. In addition, the solutions and their average for each section have been calculated.

3) Third stage update memories: In this stage, the local memory and global memory have been updated. For1 each section of the farmland, some of best solutions are stored in the local memory of that section and best solutions of these individual sections are stored in a global memory. The number of best local memory and the number of best global memory are determined according to Eqs. (30) and (31), respectively.

$$
M_{\text {local }}=\operatorname{round}(t * n), \quad 0.1<t<1
$$

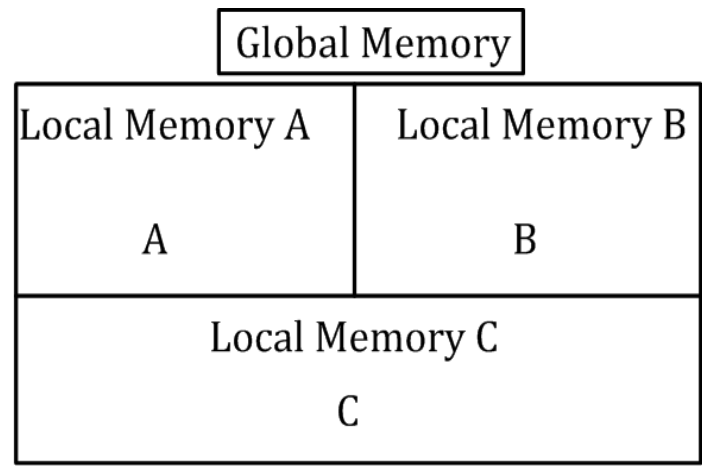

Fig. 4. Partitioned Example of Farmland and Local Memory and Global Memory.
$M_{\text {Global }}=\operatorname{round}(t * n), \quad 0.1<t<1$

where, the $M_{\text {Global }}$ express the number of stored solutions in global memory. While the number of the stored solution in local memory is $M_{\text {local }}$. Based on the fitness and suitability of the local and global memories, the solutions have been placed. Moreover, at this stage both memories are updated.

4) Fourth stage: changing quality of the soil in each section of farmland: In the third stage, the soil quality of each section has been determined using equation (28). The best solutions of each part of the farmland has been stored in the corresponding local memory. Moreover, the best solution for all sections have been stored in the global memory. In this stage, the solutions of the worst section should be updated and more changes should be happened to improve its quality. So the all existing solutions in worst section can be combined with the best solution of the global memory. This can be mathematically expressed as in Eqs. (32) and (33):

$$
\begin{aligned}
& h=\alpha * \operatorname{rand}(-1,1), \\
& X_{n e w}=h *\left(X_{i j}-X_{M_{G l o b a l}}\right)+X_{i j}
\end{aligned}
$$

where, $X_{M \text { Global }}$ is a random solution among existing solutions in the global memory and $\alpha$ is a number between zero (0) and one (1) that should be valued at the beginning of the farmland fertility. $X_{i j}$ is a solution in worst part of farmland that is selected to apply changes. Moreover, $\mathrm{h}$ is a decimal number which is computed from Eq. (32). Consequently, $X_{\text {new }}$ is the new solution. This solution has been take place to change.

After applying the previous change: For updating the solutions of other sections; a combination between the existing solutions of each section (apart from the worst section) are combined as the following equations (34) and (35):

$$
\begin{aligned}
& h=\beta * \operatorname{rand}(0,1), \\
& X_{n e w}=h *\left(X_{i j}-X_{u j}\right)+X_{i j}
\end{aligned}
$$

where, $X_{u j}$ is a random solution among existing solutions in the search area. This means that, a random solution is selected from all the existing solutions in sections. $\beta$ is a number in the range between zero (0) and one (1), which should be determined at the starting of the farmland fertility process. $X_{i j}$ is a solution belongs to the worst section and has been chosen for applying changes in the solution. $h$ is a decimal number obtained from Eq. (34). After applying changes a new solution $X_{\text {new }}$ is delivered.

5) Fifth stage: soil's combination: At this stage, as we theoretically convey algorithm in part (1), depending on the best solutions available in the local memory (Best Local $_{\text {) }}$ of each section in the final stage, farmers decide to merge each soil within the parts of farmland. Therefore, there is a provision about the combination with the best in local memory. So that, not all available solutions are combined with local memory in all sections and at this stage, in order to improve the quality of solutions in each part of farmland, some of the available 
solutions in all locations are combined with the best solution ever found $\left(\right.$ Best $\left._{\text {Global }}\right)$. The combination of considered

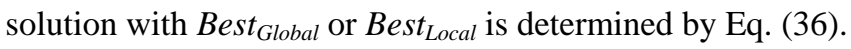

$H=\left\{\begin{array}{cc}X_{n e w}=X_{i j}+\omega_{1} *\left(X_{i j}-\text { Best }_{\text {Global }}(b)\right) & Q>\text { rand } \\ X_{\text {new }}=X_{i j}+\operatorname{rand}(0,1) *\left(X_{i j}-\text { Best }_{\text {local }}(b)\right) & \text { else }\end{array}\right.$

In Eq. (36), a new solution may be created by two different methods. In this equation, $\mathrm{Q}$ is a parameter between zero (0) and one (1) and has to be adjusted at the start of the optimization algorithm. The $\mathrm{Q}$ parameter determines to what degree the solutions are combined with best global solution $\left(\right.$ Best $\left._{\text {Global }}\right) . \omega_{1}$ is an integer number and should be evaluated at the start of the process and according to repetition of optimization algorithm its amount has been gradually decreased (Eq. (37)). $X_{i j}$ is a solution that to apply the changes is selected from all sections. As a result, according to the applied changes, a new solution $X_{\text {new }}$ has been produced.

$\omega_{1}=\omega_{1} * R_{v}, 0<R_{v}<1$

6) Sixth stage: final conditions: At this stage, the existing available solutions in search area are evaluated according to the objective function. Whatever the number of sections is, this stage is performed on all existing solutions in the search field. Thus, the fitness the degree of suitability of each of the available solutions is determined in the search space. At the end of the farmland fertility, are investigated final conditions. If we confirm final condition, the algorithm ends. Otherwise, the algorithm will continue its work to establish final conditions. The flowchart of the FFA optimization algorithm has been shown in Fig. 5.

\section{Modified FFA Algorithm}

In this paper a modified FFA algorithm has been proposed and tested. Moreover, the modified FFA algorithm is compared with the conventional FFA algorithm which presented in [36]. The modified FFA algorithm is to combine the solutions of the fourth and fifth stages to reduce the processing time of the execution of the optimization algorithm.

A new random number $m$ has been created. This random number is between 0 and 1 . This number reduces the implementation time of the algorithm. While, the FFA algorithm tries three solutions equations $(33,35$ and 35$)$ in a cascade manner which increase the processing time of the algorithm. Moreover, this random number is to determine the balancing between the local and global optimization solutions.

In the proposed FFA algorithm, the new solution is defined as a combination of equations (32)-(36) for updating the new solution best global solution in the previous iteration and random solution based on a random solution of the best solution in the local memories:

$H=\left\{\begin{array}{cc}X_{\text {new }}=X_{i j}+\omega_{1} *\left(X_{i j}-\text { Best }_{\text {Global }}(b)\right) & Q>\text { rand } \\ X_{\text {new }}=X_{i j}+\text { rand }(0,1) *\left(X_{i j}-\text { Best }_{\text {local }}(b)\right)+h *\left(X_{i j}-X_{M_{\text {Global }}}\right) & \text { else }\end{array}\right.$

where, $X_{i j}$ is a solution, which is considered to update for each section. Best Global $_{\text {is }}$ the best solution in the global memory. Best $t_{\text {Local }}$ is the best solution in the local memory. $X_{\text {MGlobal }}$ is a random solution among existing solutions in the global memory. $h$ is defined in equation 33. $\omega_{1}$ as a parameter of the farmland fertility and is updated as follows:

$\omega_{1}=\omega_{1} * R_{v}, \quad 0<R_{v}<1$

The flowchart of the proposed MFFA is shown in Fig. 6.

The optimization problem is to minimize the objective functions of equation (23) and determine the best optimal size of RES plants which are (number of PV units, number of wind turbines, rated power of the electrolyzer, maximum capacity of the hydrogen tank, rated power of the fuel cell and rated power of the DC/AC converter). In this paper, each of the proposed optimization algorithms operates according to the following steps:

1) Run the program of designing the RES based on the energy balance.

- Generation of initial population, Equation (27)

- Run the program of designing the hybrid energy system described by equations from (1) to (23) and illustrated in the flowchart of Fig. 3.

- Evaluation process of the fitness function for all agents/positions. Equation (24)

2) Run the optimization algorithm with the RES based on equations (28) and (35) as the following processes:

- Updating the position and sizing the RES elements, according the nature of each optimization algorithm.

- Run the program of designing the RES. Equations from (1) to (23) and illustrated in the flowchart of Fig. 3.

- Evaluation process of the fitness function for all agents/positions, Equation (24).

- Check if the proposed system meets end criterion, If "No", repeat the previous three processes. If "Yes", the program will be stopped and will go to the next step.

- Type the results such as sizing of system components and the best optimum values of COE and LPSP. 


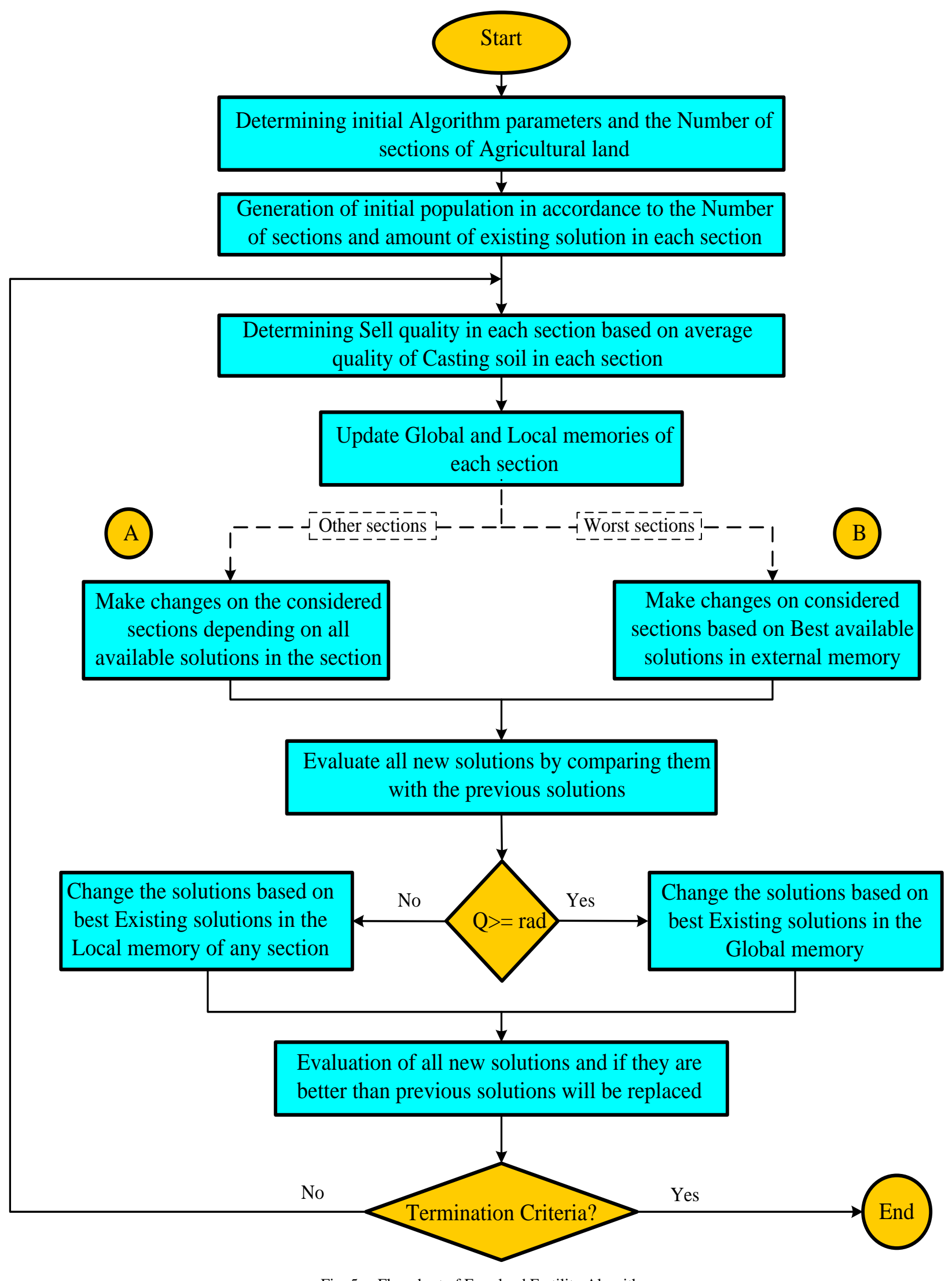

Fig. 5. Flowchart of Farmland Fertility Algorithm. 


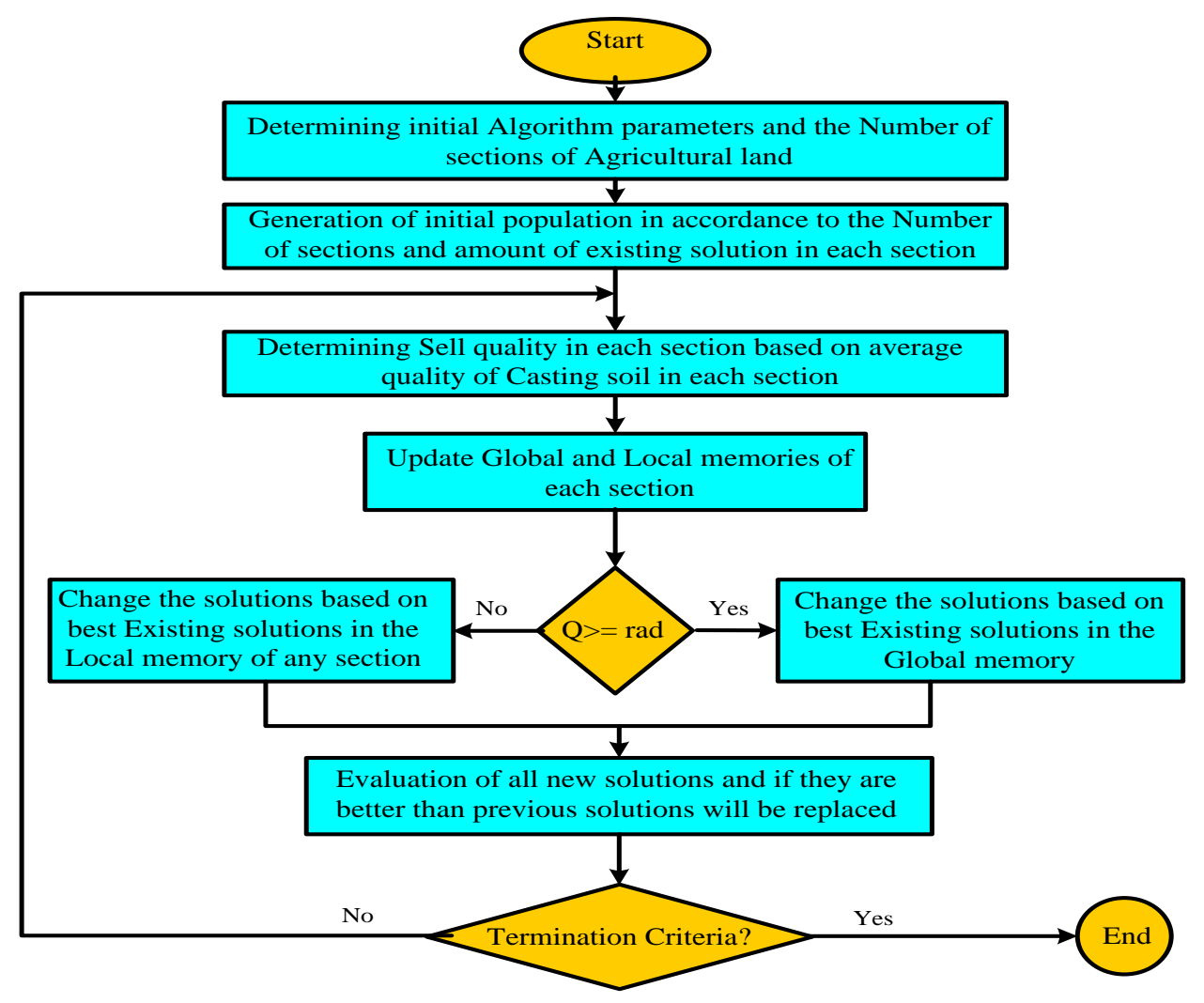

Fig. 6. Flowchart of Modified Farmland Fertility Algorithm.

\section{RESUlTS AND DISCUSSION}

To evaluate the advantages of the proposed optimization algorithm, a real case of study has been presented in order to design a hybrid renewable energy system. The case study has been selected in Ataka, Suez, Egypt. The annual load curve of the region under study is given in Fig. 7. The data of wind speeds over the year and horizontal solar radiation from 7 A.M to 16 P.M are obtained from the Egyptian Metrological Authority for Ataka site. A sample of the input data characterizing the meteorological data of the site including the intensity of solar radiation and wind speed are given in Fig. 8.

The results were accomplished using MATLAB simulation program. The parameters of the optimization algorithms FFA and MFFA are the same; the maximum number of iterations was set to 100 iterations and the maximum number of search agents is 30. In this study, the size of the proposed hybrid system is defined as the number of PV modules, the number of wind turbines, the rated power of the electrolyzer, the mass of hydrogen tank, and the rated power of the fuel cell.

Fig. 9 shows the convergence curves for the FFA and MFFA optimization algorithms. As seen from Fig. 9, both optimization techniques can reach the optimum solution of the objective function. However, the figure shows that the MFFA is faster than the FFA optimization technique. The MFFA can reach to the optimum solution in 8 iteration while the FFA algorithm reach after 11 iteration. Moreover, Table II shows the detailed results of the optimization process for the two optimization algorithms. The essential term for comparison is not only the number of iterations but also the time elapsed for implementation. The implementation time with the proposed MFFA is 3664.6 second for the 100 iteration but the time required for execution the 100 iterations with FFA is 6792.7 second. The main reason for this reduction of the implementation time is due to the conventional FFA requires 2 steps for evaluating the new solution for each iteration while the proposed MFFA does it for one step.

According to FFA optimization algorithms, to ensure the minimum COE of 0.3570 at the proposed location $70 \mathrm{PV}$ units, 100 wind turbines, the rated power of the Electrolyzer of $500 \mathrm{~kW}$, the mass of the hydrogen tank of $70 \mathrm{~kg}$, and FC with the rated power of $133.4 \mathrm{~kW}$ is estimated.

From the results, it is inferred that the both FFA and MFFA predicts minimum COE of $0.3570 \$ / \mathrm{kWh}$, which results in a net present value of 8.6204 million $\$$ and ensure the value of LPSP of $1.12 \mathrm{e}^{-19}$ which agree with the predefined value $\left(<\beta_{L}=\right.$ $0.05)$.

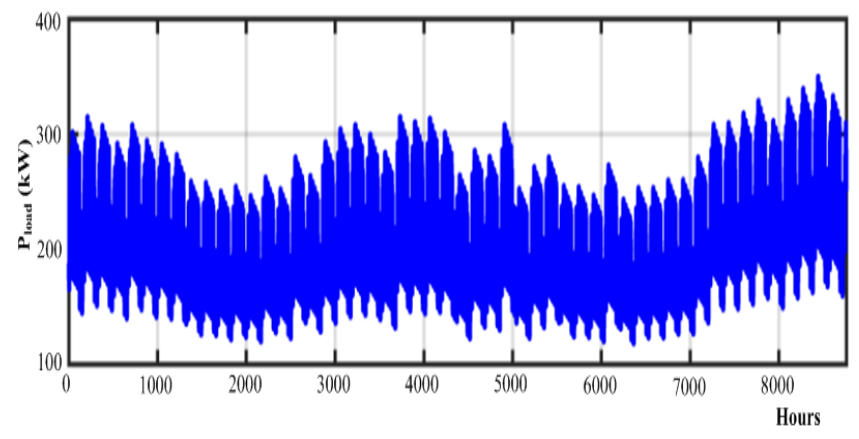

Fig. 7. Load Demand Over a Year. 


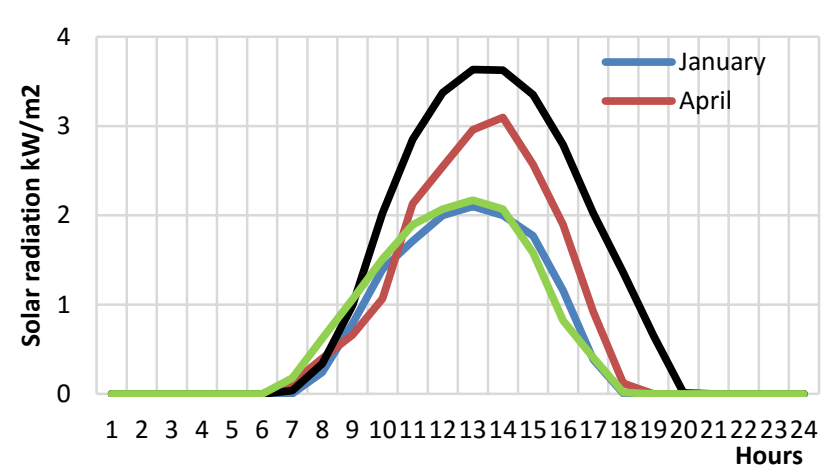

(a)

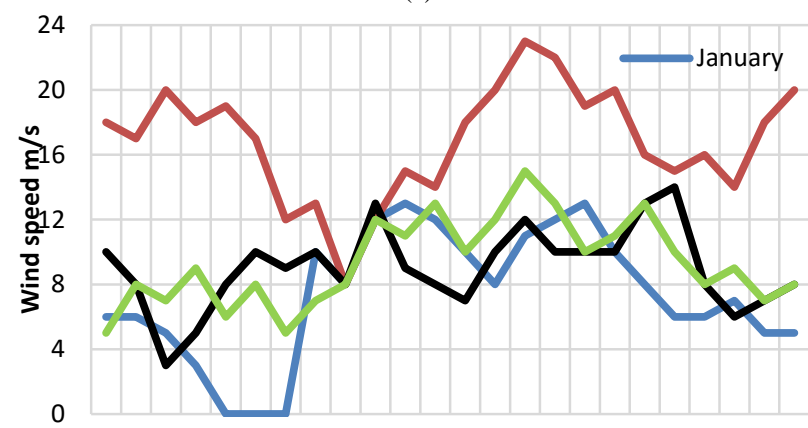

12344567899101112131415161718192021222324

(b)

Fig. 8. Annual Variation of Input Parameters; (a) Solar Irradiation, (b) Wind Speed.

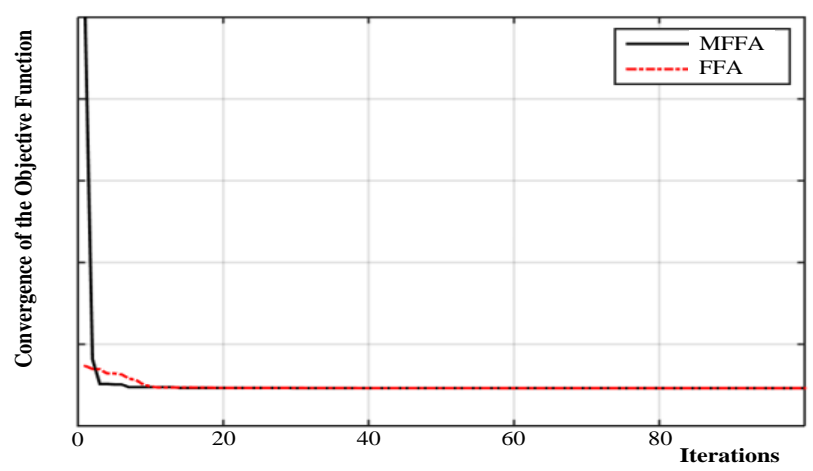

Fig. 9. Convergence Curves for the FFA and MFFA Optimization Techniques.

Fig. 10 shows the hourly variation of the generated power for the components of the proposed hybrid system at the optimum case for MFFA. The presented results from the figures are; the difference between the renewable generation and the load $\left(\mathrm{P}_{\text {diff }}\right)$, the power consumed by the electrolyzer $\left(\mathrm{P}_{\text {ELEC }}\right)$ to convert the excess electrical energy into chemical energy in the form of hydrogen, the mass of the hydrogen stored in the tanks.

$\left(\mathrm{M}_{\text {tank }}\right)$, the power generated by the fuel cell $\left(\mathrm{P}_{\mathrm{FC}}\right)$ in the case of low wind speed and insufficient solar radiation, the electric power transformed from $\mathrm{DC}$ form into $\mathrm{AC}$ power through the DC/AC converter $\left(\mathrm{P}_{\mathrm{INV}}\right)$, and finally the energy exchange with the external grid, which is represented in the form of surplus and deficit power during the operation period $\left(\mathrm{P}_{\text {sur }} \& \mathrm{P}_{\mathrm{def}}\right)$.
TABLE II. RESULTS OF THE SYSTEM DESIGNED BASED ON FFA AND MFFA

\begin{tabular}{|l|l|l|l|}
\hline \multicolumn{2}{|c|}{} & $\begin{array}{l}\text { FFA } \\
\mathbf{2 0 1 8}\end{array}$ & $\begin{array}{l}\text { MFFA } \\
\mathbf{2 0 1 9}\end{array}$ \\
\hline Best Objective Function & 0.3570 & 0.3570 \\
\hline \multirow{4}{*}{$\begin{array}{l}\text { Best } \\
\text { solution }\end{array}$} & $\boldsymbol{P V}$ (units) & 70 & 70 \\
\cline { 2 - 4 } & Wind (units) & 100 & 100 \\
\cline { 2 - 4 } & Electrolyzer $(\boldsymbol{k W})$ & 500 & 500 \\
\cline { 2 - 4 } & Hydrogen tank $(\boldsymbol{k g})$ & 70 & 70 \\
\cline { 2 - 4 } & Fuel cell $(\boldsymbol{k W})$ & 133.4 & 133.4 \\
\cline { 2 - 4 } & DC/AC converter $(\boldsymbol{k W})$ & 500 & 500 \\
\hline No of iterations for the optimal solution & 11 & 8 \\
\hline COE & 0.3570 & 0.3570 \\
\hline LPSP & $1.12 \mathrm{e}-19$ & $1.12 \mathrm{e}-19$ \\
\hline $\begin{array}{l}\text { Time of implantation (second) for 100 } \\
\text { iterations }\end{array}$ & 6792.7 & 3664.6 \\
\hline
\end{tabular}
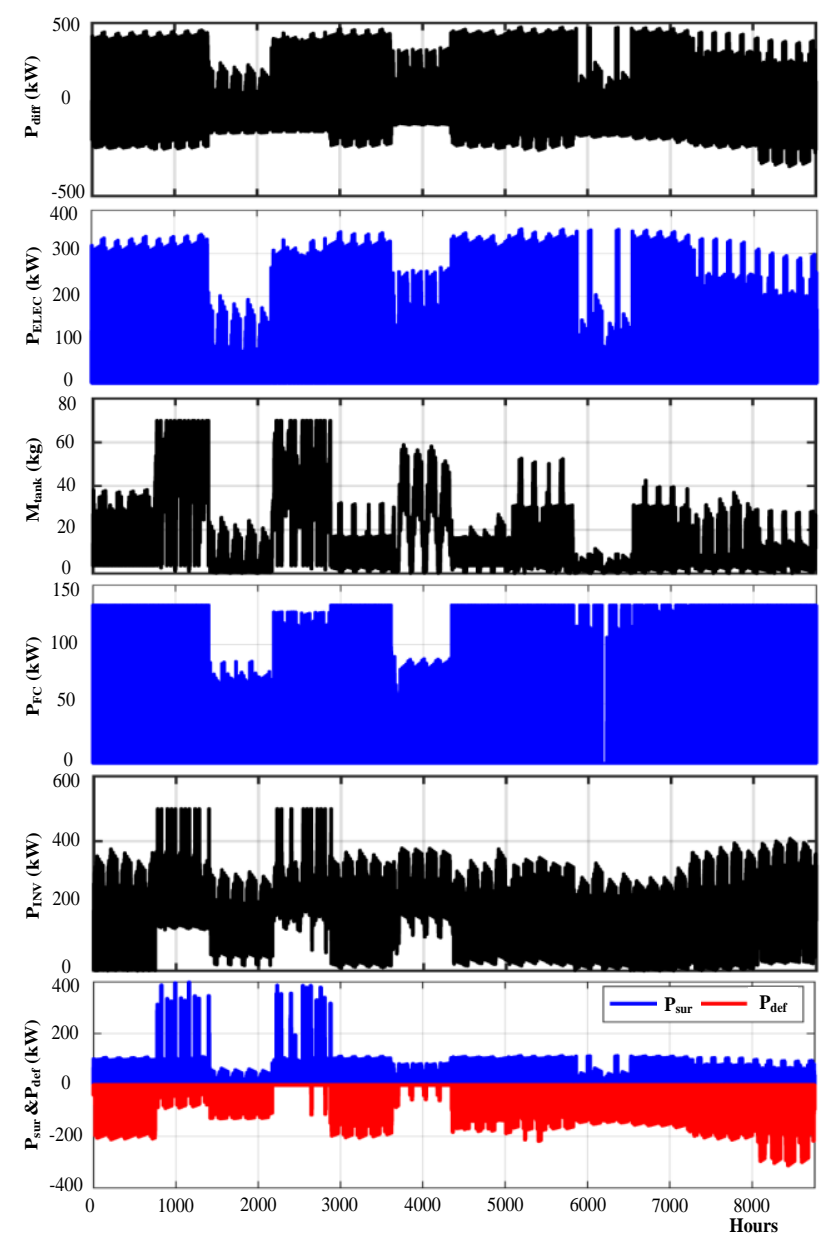

Fig. 10. MFFA Algorithm Results for the Optimal Solution.

Due to design constraints, it is very difficult to achieve the optimization requirements while keeping zero energy exchange with the grid. From the figure, it is clearly seen that almost time electric power flows to and from the external grid to cover the load demand. During the hours of high generation from the renewable sources, the excess energy is used by the electrolyzer and in turn, the mass of hydrogen in the tank 
increased. For a better understanding of the energy management strategy behind the optimization algorithms, the simulation results are concentrated for one day of operation of the hybrid system at the optimum conditions of operation as shown in Fig. 11.

Fig. 11 shows the simulation results for a certain day with respect to the optimal sizing from MFFA algorithm. From the figure, it is obvious that during late nighttime and the early hours, when the wind speed reaches it maximum values and the load demand is minimum, the generated power from the renewable sources exceeds the demand for electric energy. As a result of that, the excess power is drawn by the electrolyzer, which converts it into hydrogen. At the late hours of night of the day it is very clear from Fig. 11 that $\mathrm{M}_{\mathrm{tank}}$ increases. This scenario is repeated again during day hours when the solar radiation is maximum. During daytime when the demand for electric energy increased but the renewable generation is not enough to satisfy the load, the hydrogen stored is consumed by the fuel cell. It is obvious from Fig. 11 that $M_{\text {tank }}$ reached a maximum value then started to decrease and at that time the power generated by the fuel cell $\left(\mathrm{P}_{\mathrm{FC}}\right)$ started to increase.
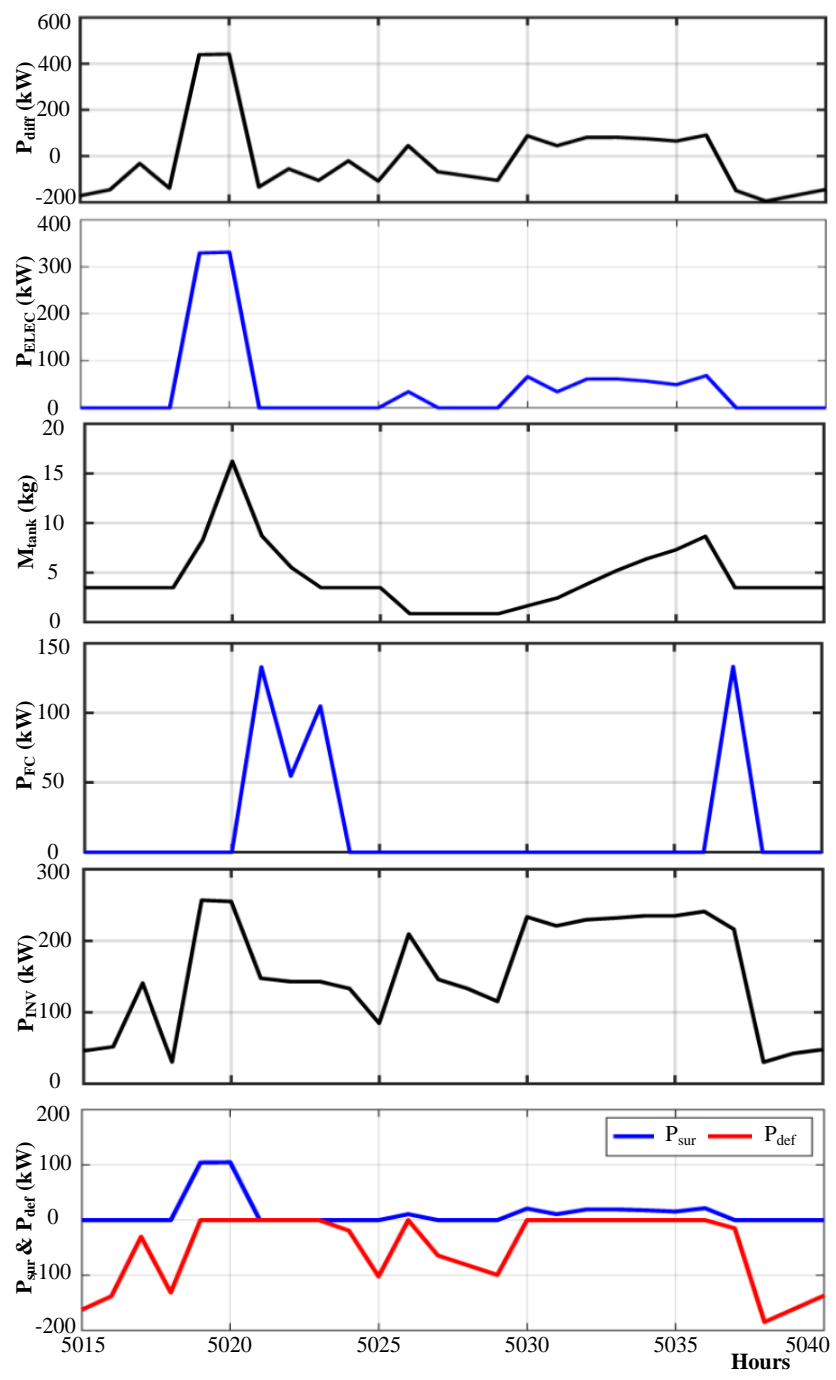

Fig. 11. Simulation Results for One Day of Operation with MFFA.

\section{CONCLUSION}

The optimal sizing and operation of a grid-connected hybrid energy system are performed. For this work, solar photovoltaic-wind turbine-fuel cell are designed and economic feasibility model is introduced through a hybrid grid-connected system. Modified Farmland Fertility Algorithm has been proposed for solving the optimization problem. The PV-windelectrolyzer-Hydrogen tank-Fuel cell system has been designed to meet the load demand with the minimum COE while ensuring a high power supply reliability, low fluctuations in the energy exchange with the external grid, and complementary use of renewable energy sources. The optimization results show that both FFA and MFFA algorithms reached the best value of the objective function of 0.357 , which represents the minimum value of the COE of $0.357 \$ / \mathrm{kWh}$. However, MFFA reached the best objective function faster than FFA algorithm. MFFA algorithm reached the minimum COE within 8 iterations, which takes an implementation time of $3664.6 \mathrm{~s}$, while FFA reached the optimal solution in 11 iterations, which takes a time of $6792.7 \mathrm{~s}$. This study will be useful for the decision makers in Egypt as a convenient solution to increase the penetration level of irregular renewable energy sources and ensuring fulltime energy supply. The next research area is to explore the role that high penetration level of large-scale PV power plants will play in short and long-term frequency stability. In addition, in hybrid PV/wind power systems the dynamic nature of these renewable sources has to be fully utilized.

\section{REFERENCES}

[1] Goedeckeb, M.; Therdthianwong, S.; Gheewala, SH. Life cycle cost analysis of alternative vehicles and fuels in Thailand. Energy Policy 2007, 35(6), 3236-3246.

[2] Kusakana, K.; Vermaak, H.J. Hybrid renewable power systems for mobile telephony base station in developing countries. Elsevier Renewable Energy 2013, 51, 419 - 425.

[3] IEA. Renewable energies for remote areas and islands; April, 2012.

[4] Bernal-Agustín, JL; Dufo-López, R. Simulation and optimization of stand-alone hybrid renewable energy systems. Renew Sustain Energy Rev 2009, 13, 2111-8.

[5] Elhadidy, MA; Shaahid, SM. Parametric study of hybrid (wind + solar + diesel) power generating systems. Renew Energy 2000, 21, 129-139.

[6] Bagul, AD; Salameh, ZM; Borowy, B. Sizing of a stand-alone hybrid wind photovoltaic system using a three-event probability density approximation. Sol Energy 1996, 56, 323-335.

[7] Ghosh, GC; Emonts, B; Stolen, D. Comparison of hydrogen storage with diesel generator system in a PV-WEC hybrid system. Sol Energy 2003, 75, 187-198.

[8] Bak, T.; Nowotny, J.; Rekas, M.; Sorrell, CC. Photo-electrochemical hydrogen generation from water using solar energy: materials-related aspects. Int J Hydrogen Energy 2002, 27, 991-1022.

[9] Kashefi, Kaviani A; Baghaee, HR; Riahy, GH. Design and optimal sizing of a photovoltaic/wind-generator system using particle swarm optimization. In Proceedings of the 22nd power system conference (PSC), Tehran, Iran, December 19-21, 2007.

[10] Khan, MJ; Iqbal, MT. Dynamic modeling and simulation of a small wind-fuel cell hybrid energy system. Renewable Energy 2005, 30, 421439.

[11] Khan, MJ; Iqbal, MT. Pre-feasibility study of stand-alone hybrid energy systems for applications in Newfoundland. Renewable Energy 2005, 30, 835-854.

[12] Mills, A; Al-Hallaj, S. Simulation of hydrogen-based hybrid systems using hybrid2. Int J Hydrogen Energy 2004, 29, 991-999. 
[13] Bernal-Agust'in, J. L.; Dufo-L'opez, R.; Rivas-Ascaso, D. M. Design of isolated hybrid systems minimizing costs and pollutant emissions. Renewable Energy 2006, 31(14), 2227- 2244.

[14] Dufo-L'opez, R.; Bernal-Agust'in, J.; Yusta-Loyo J. Multiobjective optimization minimizing cost and life cycle emissions of stand-alone PV-wind-diesel systems with batteries storage. Applied Energy 2011, 88(11), 4033-4041.

[15] Yang, H.; Zhou, W.; Lu, L.; Fang, Z. Optimal sizing method for standalone hybrid solar-wind system with LPSP technology by using genetic algorithm. Elsevier Journal of Solar Energy 2008, 82, 354-367.

[16] Bilal, B. O.; Sambou, V.; Ndiaye, P. A.; Kebe, C.; Ndongo, M. M. Optimal design of a hybrid solar-wind-battery system using the minimization of the annualized cost system and the minimization of the loss of power supply probability (LPSP). Elsevier Journal of Renewable Energy 2010, 35, 2388-2390.

[17] Tafreshi, M. S.; Zamani, H. A.; Ezzati, S. M.; Baghdadi, M. Optimal unit sizing of Distributed Energy Resources in Micro Grid using genetic algorithm. In 18th Iranian Conference on Electrical Engineering (ICEE), Isfahan, Iran, 2010.

[18] Pirhaghshenasvali, M.; Asaei, B. Optimal modeling and sizing of a practical hybrid wind/PV/diesel generation system. In 5th Power Electronics, Drive Systems and Technologies Conference (PEDSTC), Tehran, Iran, 2014.

[19] Bashir, M.; Sadeh, J. Optimal sizing of hybrid wind/photovoltaic/battery considering the uncertainty of wind and photovoltaic power using Monte Carlo. In Environment and Electrical Engineering (EEEIC), 11th International Conference on, Venice, 2012.

[20] Navaerfard; Tafreshi, S.; Barzegari, M.; Shahrood, A. Optimal sizing of distributed energy resources in microgrid considering wind energy uncertainty with respect to reliability. In IEEE International Energy Conference and Exhibition (EnergyCon), Manama, 2010.

[21] Ekren, O.; Ekren, B. Y. Size optimization of a PV/wind hybrid energy conversion system with battery storage using simulated annealing. Journal of Applied Energy 2010, 87(2), 592-598.

[22] Ekren, O.; Ekren, B. Y. Size optimization of a PV/wind hybrid energy conversion system with battery storage using response surface methodology. Journal of Applied Energy 2008, 85(11), 1086 - 1101.

[23] Arabali, M. Ghofrani, M. Etezadi-Amoli and M. S. Fadali, "Stochastic Performance Assessment and Sizing for a Hybrid Power System of Solar/Wind/Energy Storage," IEEE Transactions on Sustainable Energy 2014, 5(2), 363-371.

[24] Mohamed, Mohamed; Eltamaly, Ali; \& Alolah, Abdulrahman; Hatata, Y. A. A novel framework-based cuckoo search algorithm for sizing and optimization of grid-independent hybrid renewable energy systems.
International Journal of Green Energy 2018, 1-15. 10.1080/15435075.2018.1533837.

[25] Makbul A.M. Ramli , H.R.E.H. Bouchekara, Abdulsalam S. Alghamdi, "Optimal sizing of PV/wind/diesel hybrid microgrid system using multiobjective self-adaptive differential evolution algorithm," Renewable Energy 121 (2018) 400-411.

[26] Raviprabakaran, Dr.Vijay; Ramachandradurai, Sowmya. Optimal Sitting of PV-Wind-Energy Storage System Integrated Micro Grid Using Artificial Bee Colony Optimization Technique. International Journal of Innovative Research in Computer and Communication Engineering 2017, 5, 9640-9652.

[27] Ngan, M.; Tan, C. Assessment of economic viability for PV/wind/diesel hybrid energy system in southern Peninsular Malaysia. Renewable and Sustainable Energy Reviews 2012, 16, 634-647.

[28] Haidar, A.; John, P.; Shawal, M. Optimal configuration assessment of renewable energy in Malaysia. Renewable Energy 2011, 36, 881-888.

[29] Sultan, Hamdy M.; Diab, Ahmed A. Zaki; Kuznetsov, Oleg N.; Zubkova, Irina S. Design and evaluation of PV-wind hybrid system with hydroelectric pumped storage on the National Power System of Egypt. Global Energy Interconnection 2018, 1(3), 301-311,

[30] Koutroulis, E; Kolokotsa, D; Potirakis, A; Kalaitzakis, K. Methodology for optimal sizing of stand-alone photovoltaic/wind-generator systems using genetic algorithms. Sol Energy 2006, 80, 1072-1088.

[31] Garcia, RS; Weisser, D. A wind-diesel system with hydrogen storage: joint optimization of design and dispatch. Renewable Energy 2006, 31, 2296-2320.

[32] El-Sharkh, MY; Tanrioven, M; Rahman, A; Alam, MS. Cost related sensitivity analysis for optimal operation of a grid-parallel PEM fuel cell power plant. J Power Sources 2006, 161, 1198-1207.

[33] Kashefi, Kaviani; Riahy, G.H.; Kouhsari, SH.M. Optimal design of a reliable hydrogen-based stand-alone wind/PV generating system, considering component outages. Renewable Energy 2009, 34, 23802390.

[34] Strunz, K; Brock, EK. Stochastic energy source access management: infrastructure- integrative modular plant for sustainable hydrogenelectric cogeneration. Int J Hydrogen Energy 2006, 31, 1129-1141.

[35] Xu, L; Ruan, X; Mao, C; Zhang, B; Luo, Y. An improved optimal sizing method for wind-solar-battery hybrid power system. IEEE Trans Sustain Energy 2013; 4(3), 774-785

[36] Shayanfar, Human; Gharehchopogh, Farhad Soleimanian. Farmland fertility: A new metaheuristic algorithm for solving continuous optimization problems. Applied Soft Computing 2018, 71, 728-746.

[37] The official website of the Ministry of Electricity and Renewable Energy, New Renewable Energy Authority, Available at http://www.nrea.gov.eg/Technology/ProjectLocation. 